\title{
Impact of the Systemic Approach on Literacy Achievement of Jordanian 1st Graders at Mu'tah University Model School
}

\author{
Nail Al-hajaya \\ College of Educational Sciences, Tafila Technical University \\ P. O box 179, Tafila, Jordan \\ Tel: 96-279-950-0069 E-mail: n_hajaia@yahoo.com
}

Received: April 18, 2011

Accepted: May 3, 2011 Published: February 1, 2012

doi:10.5539/ies.v5n1p100

URL: http://dx.doi.org/10.5539/ies.v5n1p100

\begin{abstract}
This study investigates the effect of the systemic approach in literacy achievement of the first grade students at Mu'tah University's Model School. The sample $(\mathrm{N}=45)$ consisted of all first grade students, who were assigned into two groups; a control group taught traditionally while the other group was exposed to the system approach during the academic year 2008/2009. Instruments used included a number of tasks designed based on the systemic approach and achievement test with acceptable validity and reliability. Results found statistical significant difference among mean estimates of both groups, indicating effectiveness of the systemic approach in the improved achievement of students who were exposed to the systemic approach, whereas no such differences were found for the gender.
\end{abstract}

Keywords: Systemic approach, Literacy education, Literacy achievement

\section{Introduction}

Language is commonly defined as a connotative system, vocal symbolic system, a denotative relationship between meanings and words forming a system, or a peculiar scheme with specific rules. Language is, therefore, a delicate system necessitates many cognitions and skills. The communication process involves speaker-listener, or author-reader run through elaborated steps. An author, for example, who has in his mind an idea to convey, makes a selection of symbols and words-to suitably express the meaning. The selected words will then be formulated into a sentence, statement, or paragraph. To speak, one would articulate or just write the symbols down taking into account good speech or writing rules. Further, the age and educational level of the receiving audience i.e. listener or reader should be considered. The message is transmitted to listener or reader when the listener recognizes (words) heard or reader discerns the written symbols. The next step is to translate the symbols they receive into, in their views, most probable meanings. The intended meaning will be delivered from a speaker to listener or from a writer to reader when such meanings are comprehended, analyzed, explained criticized, and assessed (Madkor, 2003).

There is no one system more coherent, integrated, and concerted more than language. The traditional practice in language teaching has been to learn students separated and scattered language subjects. Young students who learn disintegrative language topics like grammar or literature, in separate of the whole system, will produce fragile reading, speaking and writing skills, with ineffective skill of recognizing the semantic vocal system of language.

Teaching Arabic language is still much more concentrated on providing students dysfunctional unsystematic bulky data. The immediate result is rote learning of Arabic with little or no applications. Learning language concepts has become incoherent, too difficult for a student to comprehend, and internalize in an integrated system. Student who learn such incoherent and disintegrated linguistic concepts feel uneasy in practical situations in which they are required to use the skills they acquired. As a result of such disintegrated view held by learners, there is a need for new approaches to be used in teaching Arabic among which the system approach is one example.

The recent research on science education supported employing the system approach in teaching such disciplines as mathematics. However, results from many other studies involving the system approach were in line with the earlier studies. In the field of Arabic teaching the perceived gap in research motivated interested authors to adopt the system approach in their studies on teaching Arabic language.

However already addressed by many studies, it is reasonable to ask what the system approach is? Primarily, the system approach has been developed based on Ausbel theory of meaningful verbal learning wherein experiences are presented schematically to demonstrate the connectivity, interactivity and interdependence between new and older 
experiences that are already stored in learner's cognitive structure. The meaningful learning, therefore, does not take place only as a result of accumulation of new facts with already acquired facts; rather the meaningful learning happens as a result of interaction of the new knowledge with what is already learned. In consequence, cognition should be a logical, integrated, and organized structure. This mechanism reduces effort needed for one learner to link such experiences together (Shehab, 2001).

The system approach also depends on the constructivist theory in which it is presumed that learning happens when new concepts and cognitions are linked with already held knowledge. Thus what the system approach makes is to shift emphasis in learning from the external (teacher-student-classroom) to internal factors. The meaningful learning will be created out of a network of interrelated concepts that facilitates concept learning, retention, and comprehension (Saudi et al, 2005). The mental processes a learner would have in learning situations such as prior knowledge, remembering, data processing, and learning styles are contributing to the meaningful learning (al-Najdi et al, 2003).

Another concept critical to the system approach is schemata, which is a set of things in one field interactively connected together to achieve specific objectives. Educators, however, find the system approach significant in order to keep up with the intricate nature of the educational problems in their field, which is affected by a number of different interactive factors (al-Said, 2004).

\subsection{The Question at this Point Is Why Using the System Approach in Arabic Teaching}

Linguists view language as a system with different components heavily dependent on each other. This system is very important to understand the language change, language itself and its role in a community (Matloub, 1987).

However, ancient Arab linguists were conscious to the systematic structure of language. In his Arabic Syntactic work al-Alfiya, Ibn Malik argued that names, verbs, and letters are the basic components of the Arabic sentence.

Socere, on the other hand, described language as chess game viewing that the mere importing of the game from the Orient into the West as extrinsic, whereas studying chess playing rules is intrinsic. Should the chess pieces change from wood into ivory the game system will be the same, but if they have been increased or decreased in number the gaming rules will be dramatically changed (Matloub, 1987).

This example illustrates the language as a system or schema having its own rules and interrelated components. For studying language, schema i.e. internal system is the most important.

Language consists of a number of interrelated sub-systems:

- Phonetic system: phonemes connected together affect and are affected by the verbal environment.

- Morphological system: includes vocabulary and how are formally changed into singular, plural, masculine and feminine forms.

- Syntax system: refers to how words are orderly associated

- Semantic system: describes how words and sentences take their meanings (al-Hamdani, 2004).

Viewed as an integrated system, language is controlled with the morphological and phonetic subsystems. Whereas the morphological system determines the strict meaning of word within the general schema, the syntax and semantics determine in what order words should be combine in a sentence that comply with inflection criteria, so that the sentence will have it accurate meaning.

As an integrated system, language has sounds, phonemes, vocabulary, and realties between words, so the one-sided view in separate of the other aspects distorts the whole picture. Language teaching is called to present language in integration. The common academic practice of segmenting language into modules is not but an attempt to make language study easier. However, language in the life use is practiced in integration and wholeness.

In this context, the perceived feature of the Arabic language is that is has its own modes which preserve the meaning. In other words, there is specific mode of weights implying certain meaning. For example words like: Katib (writer), Aalem (scientist), Shareb (drinker), Naem (sleeper) all of which denote an actor, whereas such words as Maktoob (be written), Ma'loum (be known), Mashroub (be drunk), Ma'kool (be eaten) all denote something enacted (al-Sayed, 1998).

Considering language as an integrative system, it is necessary, therefore, to revisit the way in which language is introduced to children. For example, such language subsystems as grammar, morphology, or literature which are typically taught dichotomously should be presented to children in an integrative combination reflecting a schematic system of language wherein later knowledge is linked with prior knowledge, so that learner would acquire a wholeness view to language without experiencing the artificial separation between reading and writing skills, or 
language and grammar.

\subsection{Arabic Teaching}

The rationale behind this study is the perceived ineffective Arabic teaching practices and the parochial approaches to language teaching, in general and Arabic teaching in particular. To summarize, the following are suggested as starting points justifying making a shift in Arabic teaching paradigm:

- Children in common maintain difficulty in learning literacy skills so it is needed to prepare pre-service teachers for language teaching, particularly writing and speaking skills.

- Recent instructional approaches view language in wholeness, so dichotomous introduction of language as separate disciplines compromises the language use in life situations.

- Classroom teachers most often report reluctance by their students towards grammar subject who find it difficult to grasp the grammatical rules enabling them to speak or write in proper language.

- The current technological advances and accompanying language teaching problems impose new methods as older ones have proven ineffective.

- In particular, Arabic lacks a systemic wholeness view yielding dissociated language disciplines and incoherence between language textbooks.

- The recent technology-based developments in the teaching aids and means that help acquiring larger and wider language concepts with varied means fit different levels.

The system approach that emphasizes student apprehension nature and role of concepts and their interrelationships helps meaningful learning in students.

- The systemic introduction of the educational experiences to help students harmonize the cognitive, emotional, and senso-motor aspects of their learning experience (al-Said, 2004).

All the above necessitates revisiting the current Arabic teaching approaches in search for new ones for purpose of developing Arabic literacy skills.

Presenting some illustrative examples showing the systematic language concepts, their interrelationships, and roles are required. However, taking an integrative and wholeness view to language in which subsystems work consistently to achieve text accuracy, intelligibility, and readability.

It is advised to teach Arabic language for learners as an integrative system from where to derive other subsystems that to be taught from its relative position against the whole system.

\subsection{Literature Review}

Fahmi \& Abdussabour (2001) conducted a study aimed at identifying the effectiveness of the system approach in facing educational challenges in present and future at public education and university levels. Results found statistically significant differences between the system approach-based teaching method and the traditional method, and differences were in favor of participants exposed to the system approach-based instruction. The study recommended application of the system approach in the educational process in light of the larger system theory.

Center for the virtual University (2001) conducted a study entitled "System Approach to Design Learning Activities on the Web" supported that the educational use of the system approach to design learning activities on the World Wide Web (Internet) saves time and produces meaningful learning. Relying on the system approach, the study proposed a 7-step strategy to design online learning activities, where (1-4) steps show how to think about the textbook and clearly identify the intended learning outcomes. However, steps (5-7) are used to link between the varied online illustrations, suggesting how a teacher should customize the numerous technological possibilities in designing a combination of effective instructional activities. Results demonstrated positive use of the system approach in designing online instructional activities which saves time and produces meaningful learning. The seven steps already indicated represented the website map that provide teachers the opportunity to think throughout the curriculum from beginning to end, and on learning by giving examples of the integration between technology and textbook. Those steps are: setting the general instructional objectives of the textbook, linking teaching with the general textbook goals, designing proper learning sequence, building activities, involving students, using means that are suiTable to the instructional activities.

Al-Said (2002) conducted a survey study for the purpose of identifying effectiveness of using the system approach in engineering education for sustainable development. The systematic electromechanical curriculum proved effectiveness of the system approach, provide competitive edge to engineers, identify skills required for the intended work, and was helpful in linking basic and applied cognitions interactively with the engineer's background 
knowledge. Results indicated that the system approach empowered the experimental group produce quality performance compared with their counterparts who did not practice the skills under study.

Al-Nimire's study (2004) aimed at exploring the effect of using system approach in teaching triangulation on achievement and higher order thinking skills among the first secondary students during the 2nd semester. The sample $(\mathrm{N}=100)$ consisted of first secondary grade students in the Qalubiya District assigned to experimental and control groups. The experimental group administered two versions of the achievement test, and the system higher order thinking skills was administered as pretest and posttest. Results found a statistically significant differences at $(\alpha=0.05)$ among both groups.

Al-Qaderi's study (2006) aimed to identify the effect of science instruction using the holistic cognitive system approach on the developed scientific thinking skills among primary 4th grade students in comparison with the traditional method. The sample $(\mathrm{N}=160)$ consisted of primary 4th grade students was randomly selected with the cluster method from public schools within Al-Kora Provincial Directorate of Education. Participants were assigned to eight classrooms, four classrooms; two for males and two for females served as experimental and four classrooms; two for males and two for females served as control groups. The experimental group was taught the Light Unit selected from the Primary 4th Textbook based on the holistic cognitive system approach, whereas the control group taught the same unit traditionally. The scientific thinking skills scale was developed which found differences in favor of the system approach-based group; whereas no such differences were found attribuTable to gender.

\subsection{Statement of the Problem and Study Questions}

Despite the wide stride brought about by education, teachers still experience perceived difficulty in literacy education with young students. Similarly, young learners find it difficult to learn how to read and write. Still others lag behind their counterparts described as slow learners. The system approach which is based on the concept of system or schema represents the relatively recent teaching approaches. Research concerned with the system approach (al-Nimer, 2006; al-Qadiri, 2006; al-Shrbini, 2005; al-Hakmi, 2003) has demonstrated the effectiveness of this approach in the improved acquisition of concepts. This study questions whether the system approach will have the same effectiveness with literacy learning? The problem addressed by this study can be specifically stated as being to inquire the effect of teaching based on system approach on literacy achievement among primary first grade students attending the Model School managed by Mu'tah University. Specifically, the present study attempts to answer the following questions:

- Are there statistically significant differences at $(\alpha \geq 0.05)$ level in reading achievement by primary first grade students attributed to the teaching method (system approach vs. traditional methods) or to the gender of participants (male vs. female)?

- Are there statistically significant differences at $(\alpha \geq 0.05)$ level in writing achievement by primary first grade students attributed to the teaching method (system approach vs. traditional methods) or to the gender of participants (male vs. female)?

\subsection{Significance of the Study}

The significance of the present study stems from the issue it addresses; it makes literacy easier and facilitates task for young children to perform. To the best knowledge of the author, this is the first study to investigate the effect of the system approach on the achievement of the primary first grade students the reading and writing skills. The importance of the present study also derives from the population it targets. Several studies had been conducted for the purpose of facilitating the literacy among young children. Along such lines, this study will hopefully provide literacy educators with new approach that better improves their learning.

\subsection{Limitations}

This study is limited to the primary first grade students attending Mu'tah University Model School during the academic year 2007/2008 and the results will be restricted by the psychometric characteristics of the instruments involved in this study.

\subsection{Variables}

This is a quasi-experimental study involving the following variables:

\subsubsection{Independent Variables}

Teaching Method: Involves two levels (traditional versus system approach teaching methods)

Gender: Involves two levels: Male/Female

1.7.2 Dependent Variable: Involves one level, i.e. student's achievement 


\subsection{Operational Definition}

Achievement: refers to the acquisition of the analysis and synthesis skills reading by the primary first grade students in the Model School during the academic year 2007/2008 and measured through their responses to activities specifically designed to that end.

System Approach in Teaching: a set of activities enhanced by graphics and illustrations related to the literacy analysis and synthesis skills forming a system of associated letters depending on the system approach-based teaching method.

\subsection{Traditional Method}

Literacy teaching method typically followed in schools throughout the Hashemite Kingdom of Jordan.

\subsection{Methods and Procedures}

\subsubsection{Population and Sample}

Population $(\mathrm{N}=45)$ consisted of the all students attending the primary first grade level at the Mu'tah University's Model School during the academic year 2008/2008. Participants were assigned to A and B classrooms relying on their GPA's in the kindergarten so that to ensure relative equivalence between both classrooms in terms of student GPA's.

Participants in this study were assigned to classroom (A), (N=23) and classroom (B). (N=22), one was selected to serve as experimental and the other as control groups, and the sample was represented by the entire participating students.

\subsection{Instrumentation}

\subsubsection{Tasks}

A number of tasks designed based on the system approach were selected and modified to fit the curricula used at Mu'tah University's Model School and rated by a number of referees from faculty members at Mu'tah and Tafila Technical universities as well as a number of primary school educational supervisors from the Jordanian Ministry of Education. However, little notes received, necessary changes were made to the tasks accordingly (tasks available from the author).

\subsubsection{Achievement Test}

The achievement test consisted of a set of exercises and multiple-choice questions, incomplete sentences, letter matching, and encircling a letter.

- Content analysis of the material presented to students was carried out taking into account the intended outcomes from the program. The author tabulated features of the test in terms of question numbers and levels. Having formulated test items, the scale was shown to nine faculty members asking their comments. In light of their notes, the author adjusted the tests and administered to a pilot study other than the original sample. Three weeks later, the tests was re-administered to the same pilot study to achieve a number of objectives:

i- $\quad$ To identify time required to complete the test

ii- $\quad$ To intelligibly test students

iii- To confirm test reliability (76.0\%), which considered sitable for the purpose of the present study.

\subsection{Results and Discussion}

Insert table 1 in here.

Group equivalence was attained through results from the two-way analysis of variance of student classrooms in Arabic during their kindergarten (preschool) level by such variables as group (experimental, control) and gender (male, female) as shown in Table 1. The table shows no statistically significant differences in student grades in the Arabic subject attributed to gender, group or their interaction implying equivalence between groups.

1.13.1 To answer the major study questions

Are there statistically significant differences at $(\alpha \geq 0.05)$ in first grade student achievements attributed to the teaching method (system approach versus traditional) and gender?

Insert table 2 in here.

To answer this question, means, standard deviations and two-way analysis of variance were employed with student grades on the literacy test as dependent variable and teaching method (system approach versus traditional) and 
gender as independent variables as shown by Table 2 .

As shown in Table 2, mean grade $(\mathrm{M}=15.74 ; \mathrm{SD}=1.71)$ of students taught with system approach method was higher than student who were taught traditionally $(\mathrm{M}=12.41 ; \mathrm{SD}=2.79)$. Two way analysis of variance was used to reveal whether mean differences were significant.

Results from the two-way analysis of variance showed statistically significant differences $(M=15.74)$ among student grades on the literacy test in favor of the experimental group, whereas no such statistical differences were found attributed to gender or teaching method and gender interaction.

The conclusion is that students exposed to the system approach-based instructions outperformed their counterparts who were taught traditionally. This result can be accounted for by the motivational effect of the system approach in instruction, which enhanced students' learning and interaction. The result of no positive effect of gender would be explained by the similar conditions the participant exposed to by all participants, their educational level, relatively younger age of participants, which mitigated the effect of physiological differences between males and females, which in turn frustrated perceivable differences in the achievement levels. These results receive support from prior studies (Al-Qaderi, 2006, Nimer, 2004, Al-Said, 2002; Centeror, 2001; Fahmi \& Abdussabour, 2001).

\subsubsection{Question 2}

Are there statistically significant differences at $(\alpha \geq 0.05)$ among primary first grade student writing achievement attributed to the teaching method (system approach versus traditional method) and gender?

To answer this question, means, standard deviations, and two-way analysis of variance were used with student grades on the writing test being the dependent variable and teaching method (system approach, and traditional method) and gender as independent variables as shown by the following Table.

Insert table 4 in here.

Table 4 shows higher mean grade $(M=16.0 ; \mathrm{SD}=1.35)$ obtained by student taught relying on the system approach compared with those taught traditionally $(\mathrm{M}=11.95 ; \mathrm{SD}=1.73)$. Results from the two-way analysis of variance are presented in Table 5.

Insert table 5 in here.

Table 5 shows statistically significant differences in student grades $(M=16.0)$ on the writing test attributed to teaching method and in favor on the system approach, whereas no such differences were found can be attributable to gender or to interaction between gender and method.

This result supports the effectiveness of the system approach in improving the writing skills in students and raising their excitement level, which in turn raises the motivation and shifts achievement level higher. The result of no statistically significant differences attributable to gender would be explained by their somewhat similar educational levels, which resulted in similar conditions in the classroom, yielding negligible achievement differences among males and females.

In light of the previous results, this study recommends the system approach as a significant approach for Arabic literacy, improving Arabic reading and writing skills and teaching systematic thinking to younger students through the intensive use of the system approach in other educational disciplines and curricula.

\section{References}

Al-Hamdani, Mowafaq. (2004). Psychology from Cognitive Perspective, Al-Masira Publishers, Amman.

Al-Najdi, Ahmad et al (2003). Science Education in the Contemporary World: Modern Science teaching Methods, Techniques and Strategies, Cairo, Arabic Thought Publishers.

Al-Nimir, Abdelqader. (2006). Effect of Using the System Approach in Teaching Triangulation on Achievement, Higher-Order Thinking Skills in first Secondary Graders. Paper presented to the $2^{\text {nd }}$ Jordan-Egyptian Conference on the System Approach and Applications in Difference Disciplines, Tafila Technology University, 18-20 July, Tafila.

Al-Qaderi, Suleiman. (2004). Whole Cognitive System Approach in Teaching Scientific Concepts. Paper presented to the $4^{\text {th }}$ Arabic Conference on System Approach to Teaching and Learning, Cairo, Dar Al-Diyafa, Ein Shams (3-4) April, Egypt.

Al-Said, Aziz Ibrahim. (2002). System Approach in Engineering Education for Sustainable Development. Paper presented to the $2^{\text {nd }}$ Arabic Conference on System Approach in Teaching and Education, Science Development Center, Ein Shams University, Cairo, Egypt. 
Al-Said, Rida. (2004). Scientific Research Linear Versus System Techniques. $4^{\text {th }}$ Conference on System Approach in Teaching, Al-Diyafa Publishers, Ein Shams University, 3-4 April, 2004, Cairo.

Al-Sayed, Mahmoud Ahmad. (1998). On Arabic Language Teaching Methods, Damascus University Publications, Damascus.

Al-Sherbini, Muhyiddin. (2005). Effectiveness of a Proposed Program for Developing Life Skills Associated with Science Teaching to Student Teachers in the Faculties of Education. Paper presented to the $5^{\text {th }}$ Arabic Conference on Approach in Teaching and Education, Cairo, April.

Amer, Fakhriddin. (2000). Arabic Language and Islamic Education Teaching Methods, Books World, Cairo.

Center for the virtual University \& Center for Teaching and learning. (2001) systems Approach [Online] Available: http://www.umuc.edu/virtualteaching/modul/Systemes.htm

Fahmi, Farouq. (2002). Systematicity and Future Challenges, Science Developing Center, Ein Shams University, Cairo. Paper presented to the 2nd Arabic Conference on System Approach in Teaching and Learning.

Fahmi, Farouq; Abdessabour, Muna. (2001). System Approach in Face of Contemporary and Future Educational Challenges, Dar Al-Ma'aref, Cairo.

Madkour, Ali Ahmad. (2003). Education and Technology Culture. Arab Thought Publishers, Cairo.

Matloub, Ahmad. (1987). Language Studies, Thought Publishers, Amman

Saudi, Muna Abdulhadi; Shehab, Muna Abdessabour; \& Al-Sa'di, Al-Sa'di Al-Ghoul. (2005). Effectiveness of System Approach-based Science Teaching on Development of Data Generation, Evaluation, and Metacognitive Thinking Skills in Middle School Students in the Arab Republic of Egypt, $5^{\text {th }}$ Conference on System Approach in Teaching and Education, April

Shehab, Muna Abdessabour. (2001). System Approach and Data Organization. Paper presented to the first Arabic Conference on System Approach in Teaching and Education. Science Education Center, 17-18, February.

Ussor, Husni Abdelbari. (1999). Issues in Teaching-Leaning Arabic Language, Modern Arabic Office, Alexandria.

Table 1. Two-way analysis of variance test of student grades in Arabic by gender and group

\begin{tabular}{|l|c|c|c|c|c|}
\hline Variance & Total Squares & Freedom Degree & Mean Squares & F-Value & $\boldsymbol{\alpha}$ \\
\hline Gender & 4.915 & 1 & 4.915 & 0.64 & 0.428 \\
\hline Group & 0.72 & 1 & 0.72 & 0.094 & 0.761 \\
\hline Gender & 0.325 & 1 & 0.325 & 0.042 & 0.838 \\
\hline Group & & & & & \\
\hline Error & 314.992 & 41 & 7.683 & & \\
\hline Total & 3632.3 & 45 & & & \\
\hline Adjusted Total & 321.2 & 44 & & & \\
\hline
\end{tabular}

Table 2. Means and standard deviations of student grades on the test by teaching method

\begin{tabular}{|l|c|c|}
\hline Teaching Method & $M$ & $S D$ \\
\hline System Approach & 15.74 & 1.71 \\
\hline Traditional Method & 12.41 & 2.79 \\
\hline
\end{tabular}


Table 3. Two-way analysis of variance of student grades by teaching method and gender

\begin{tabular}{|l|c|c|c|c|c|}
\hline Variance & Total Squares & Freedom Degree & Mean Squares & F-Value & $\boldsymbol{\alpha}$ \\
\hline Teaching Method & 121.876 & 1 & 121.876 & 22.226 & $0.00^{*}$ \\
\hline Gender & 0.863 & 1 & 0.893 & 0.163 & 0.689 \\
\hline Teaching Method & 2.108 & 1 & 2.108 & 0.384 & 0.539 \\
\hline Gender* & & & & & \\
\hline Error & 224.82 & 41 & 5.483 & & \\
\hline Total & 9313 & 45 & & & \\
\hline Adjusted Total & 352.444 & 44 & & & \\
\hline
\end{tabular}

* significant

Table 4. Means and standard deviations of student grades on the writing test by teaching method

\begin{tabular}{|l|c|c|}
\hline Teaching Method & $M$ & $S D$ \\
\hline System Approach & 16.0 & 1.35 \\
\hline Traditional Method & 11.95 & 1.73 \\
\hline
\end{tabular}

Table 5. Two-way analysis of variance among student writing grades by teaching method and gender

\begin{tabular}{|l|c|c|c|c|c|}
\hline Variance & Total Squares & Freedom Degree & Mean Squares & F-Value & $\boldsymbol{\alpha}$ \\
\hline Teaching Method & 185.275 & 1 & 185.275 & 75.25 & $* 0.00$ \\
\hline Gender & 1.817 & 1 & 1.817 & 0.738 & 0.395 \\
\hline *Teaching Method & 0.16 & 1 & 0.16 & 0.065 & 0.8 \\
\hline Gender & & & & & \\
\hline Error & 100.948 & 41 & 2.462 & & \\
\hline Total & 9135 & 45 & & & \\
\hline Adjusted Total & 286.978 & 44 & & & \\
\hline
\end{tabular}

